\title{
Consumer knowledge and perceptions of milk fat in Denmark, the United Kingdom, and the United States
}

\author{
E. Vargas-Bello-Pérez, ${ }^{1 *} \oplus$ I. Faber, ${ }^{2} \odot$ J. S. Osorio, ${ }^{3} \odot$ and S. Stergiadis ${ }^{4} \odot$ \\ ${ }^{1}$ University of Copenhagen, Department of Veterinary and Animal Sciences, Grønnegårdsvej 3, DK-1870 Frederiksberg C, Denmark \\ 2University of Copenhagen, Department of Food Science, Rolighedsvej 26, 1958 Frederiksberg C, Denmark \\ ${ }^{3}$ South Dakota State University, Dairy and Food Science Department, 1111 College Ave., Brookings 57007 \\ ${ }^{4}$ University of Reading, School of Agriculture, Policy and Development, Department of Animal Sciences, Earley Gate, PO Box 237, \\ Reading RG6 6AR, United Kingdom
}

\section{ABSTRACT}

This study examined the relationship between consumers' country of origin: Denmark (DK), the United Kingdom (UK), and the United States (US) and their knowledge and perceptions of milk fat. Adult participants answered a web-based survey, and data were collected online from December 2018 to April 2019, in DK, the UK, and the US. A total of 694 participants completed the online survey. Most respondents were between 18 and 39 years old, female, highly educated, and employed. Most UK respondents consumed milk daily (73\%), whereas in DK (56\%) and the US (46\%) consumption was significantly lower. Whole milk and semi-skim milk were consumed less by respondents in DK (20 and $36 \%$, respectively) compared with the UK (50 and 49\%, respectively) and the US (47 and 50\%, respectively). Danish respondents (53\%) consumed more skim milk than respondents from the UK (16\%) and the US (19\%). Concern about milk fat was higher in DK (60\%) than in the UK (34\%) and the US (31\%). More respondents considered milk fat to be "healthy" or "very healthy" in the UK (31 and 10\%, respectively) and the US (37 and 19\%, respectively), than in DK (23 and $6 \%$, respectively). Nutritional benefit was the most important reason for perceiving milk fat as healthy in the 3 countries. Awareness of milk saturated fat was higher among respondents from the UK (53\%) than from DK (44\%) and the US (38\%). Results suggest that consumers in DK are different in their perceptions of milk fat, but consumers in the UK and the US share common characteristics.

Received September 6, 2019.

Accepted January 22, 2020.

*Correspondence: evargasb@sund.ku.dk
Key words: consumer perception, knowledge, milk consumption, milk fat

\section{INTRODUCTION}

In the past 2 decades, a great deal of research has emphasized the role of dairy fat in the prevention of coronary disease ( $\mathrm{Yu}$ and $\mathrm{Hu}, 2018$ ) and some types of cancer (Um et al., 2019). Milk lipids in the human diet, are a good source of energy, fat-soluble vitamins (A, D, E, K), and essential fatty acids (O'Brien and O'Connor, 2016).

The profile of milk fatty acids has an effect on milk quality, physical properties (important for milk processing), nutritional value for humans (Vargas-Bello-Pérez and Garnsworthy, 2013), and sensory characteristics (McCarthy et al., 2017). Many studies have focused on improving the milk fatty acids profile, and this has led to changes in the sensory characteristics of dairy products (Markey et al., 2017).

Milk and dairy products are consumed frequently and widely, but small changes in their consumption can result in large effects on the health of a population; for example, in some cases they have been positively associated with the development of some type of cancers (Wang et al., 2017). Milk consumption is driven by sociodemographic characteristics, consumer knowledge, and consumer perceptions of milk nutrients (VargasBello-Pérez et al., 2018). Another important driver for food consumption is related to regulations (Kearney, 2010). For example, Denmark was the first country to regulate the consumption of trans fats (Astrup, 2006), a decision that was reflected later in other developed countries. According to the Food and Agriculture Organization of the United Nations and the Organization for Economic Cooperation and Development, the per capita consumption per year of processed dairy products $(10 \mathrm{~kg}$; butter, cheese, skim milk powder, and whole milk powder) and fresh dairy products $(15 \mathrm{~kg})$ in 
milk solids is similar for the European Union and the United States (OECD-FAO, 2020).

The country of origin is an important factor influencing consumers' knowledge and perceptions of foods and purchasing behavior (Adina et al., 2015). Consumer studies about perception and knowledge of food and nutrition (e.g., fats and fatty acids) are relevant to the public health sector, because they can provide insights into how to improve consumer knowledge or awareness of nutritional information (Diekman and Malcolm, 2009).

Until now, surveys related to dietary fats have focused on the general knowledge of consumers from
France, the United States, and Canada (Saulais et al., 2012), and perceptions of consumers from Belgium, Brazil, the Czech Republic, France, Germany, Greece, Indonesia, Mexico, the Netherlands, Poland, South Africa, Spain, Sweden, Turkey, the United Kingdom, and the United States (Diekman and Malcolm, 2009). To our knowledge, no cross-country studies have been done with particular emphasis on consumer knowledge and perceptions of milk fat. The objective of this study was to evaluate knowledge and perceptions of milk fat from consumers in Denmark (DK), the United Kingdom (UK), and the United States (US). Although dairy products are a common part of the diet in DK, the UK,

Table 1. Survey questions and choices

Question
Sociodemographic information
1. What is your age?
2. What is your sex?
3. What is the highest level of education you have completed?
4. What is your employment status?
5. In which country do you live?
6. Did you grow up in the countryside?
Consumption
7. Do you consume milk?
8. What is the reason you do not consume milk?

9. How often do you consume milk?

10. What type of milk do you consume more often?

11. Do you consume plant-based milk (e.g., based on soybeans, oats, or almonds)?

Knowledge

12. How would you prioritize the following nutrients when you relate them to milk? Please rank from 1 (most important) to 6 (least important) or I don't care

13. Which of the following types of milk fat do you know?

Perception

14. Are you concerned about the fat content in milk?

15. In your opinion, which of the following concepts do you relate to the fat content in milk?

16. To what extent do you think that the fat in milk is healthy?

17. Why do you think that milk fat is healthy?

18. Why do you think that milk fat is unhealthy?

Source of information and willingness to pay

19. From what source did you get your information about milk fat?

20. From which of the following health professionals do you get advice on healthy eating?

21. Are you willing to pay more for milk with a healthier fat content?
Choices

Free-choice answer

Male; female

Primary education; secondary education or vocational education; bachelor's, master's, or $\mathrm{PhD}$

Employed; unemployed; retired; student

Denmark; United Kingdom; United States

Yes; no

Yes; no

Lactose intolerance; allergy; health concern; ethical treatment of animals; sustainability concern; concern about added hormones or antibiotics; dislike

Every day; $3-6$ times per week; $1-2$ times per week; $2-3$ times per month; Less than once a month; Never

Whole (about $3.5 \%$ fat); semi-skimmed (about $2 \%$ fat); skimmed

(less than $0.5 \%$ fat); lactose-free; fortified (e.g., with added vitamins, minerals); fermented (e.g., with probiotics); flavored (e.g., chocolate, vanilla); organic

Yes; no

Energy; protein; carbohydrates (including lactose); fat; calcium; vitamins

Omega-3; omega-6; essential fat; saturated fat; monounsaturated fat; polyunsaturated fat; trans fat; I don't know

Yes; no; I don't care

Healthy; unhealthy; tasty; useful for cooking; other

Very healthy; healthy; slightly healthy; neither healthy nor unhealthy; slightly unhealthy; unhealthy; very unhealthy Nutritional benefits; energy source; lower risk of diabetes; natural product; other

Cholesterol level; obesity; diabetes; cancer; cardiovascular disease; other

TV and radio; social media; newspaper and magazines; journals and books; education (e.g., school or university); family; friends and colleagues; other

I do not seek advice; general practitioner; dietitian; hospital

doctor; practice nurse; health visitor (e.g., nurse)

Yes; no; I don't care 
and the US, we hypothesized that consumers' knowledge and perception of milk fat from these countries would be different.

\section{MATERIALS AND METHODS}

\section{Data Collection and Participants}

Data were collected via a Danish and English webbased survey (SurveyXact, www.surveyxact.com), from December 2018 to April 2019 in DK, the US, and the UK. The survey link was sent to the email lists of several organizations (University of Copenhagen, University of Reading, and South Dakota State University) and circulated through social media outlets (e.g., Facebook and Twitter). Collected data were anonymous; they included no personally identifiable information such as name or mailing address. Respondents were included in the analysis if they were $18 \mathrm{yr}$ of age or older. To make comparisons between countries, we targeted similar sample sizes. The decision to close the survey was made when response rates started to decline (fewer than 5 answered surveys per week) and similar sample sizes for each country were reached. Before data collection, a total sample size of 384 was determined via Cochran's formula, with an estimation error of $5 \%$ and $\alpha=0.05$ (Bartlett et al., 2001).

\section{Questionnaire Development}

The questionnaire had 21 questions and was divided into the following sections: (1) sociodemographic information (age, sex, education, employment status, country, grew up in the countryside); (2) type and frequency of milk consumption; (3) knowledge about milk nutrients, including fatty acids; (4) perception of milk fat; (5) sources of information about milk fat and healthy eating; and (6) willingness to pay for milk with healthier fat content (Table 1). The question "Do you consume milk?" was considered a dichotomous variable. If the answer was "yes," the participant was asked to continue to answer questions about their type and frequency of milk consumption; if the answer was "no," the participant was asked to answer the question "What is the reason you do not consume milk?" The questions used consumer-friendly language to ensure that answers accurately reflected knowledge and perceptions. The questions used for this study were adapted from similar surveys on dietary fat (Diekman and Malcolm, 2009; Saulais et al., 2012) and milk consumption (VargasBello-Pérez et al., 2018).

Before we used the final questionnaire, we performed a pilot survey among 30 participants to evaluate the questions in terms of clarity, accuracy of response options, use of scientific terminology, and the overall flow

Table 2. Characteristics of participants from Denmark, the United Kingdom, and the United States

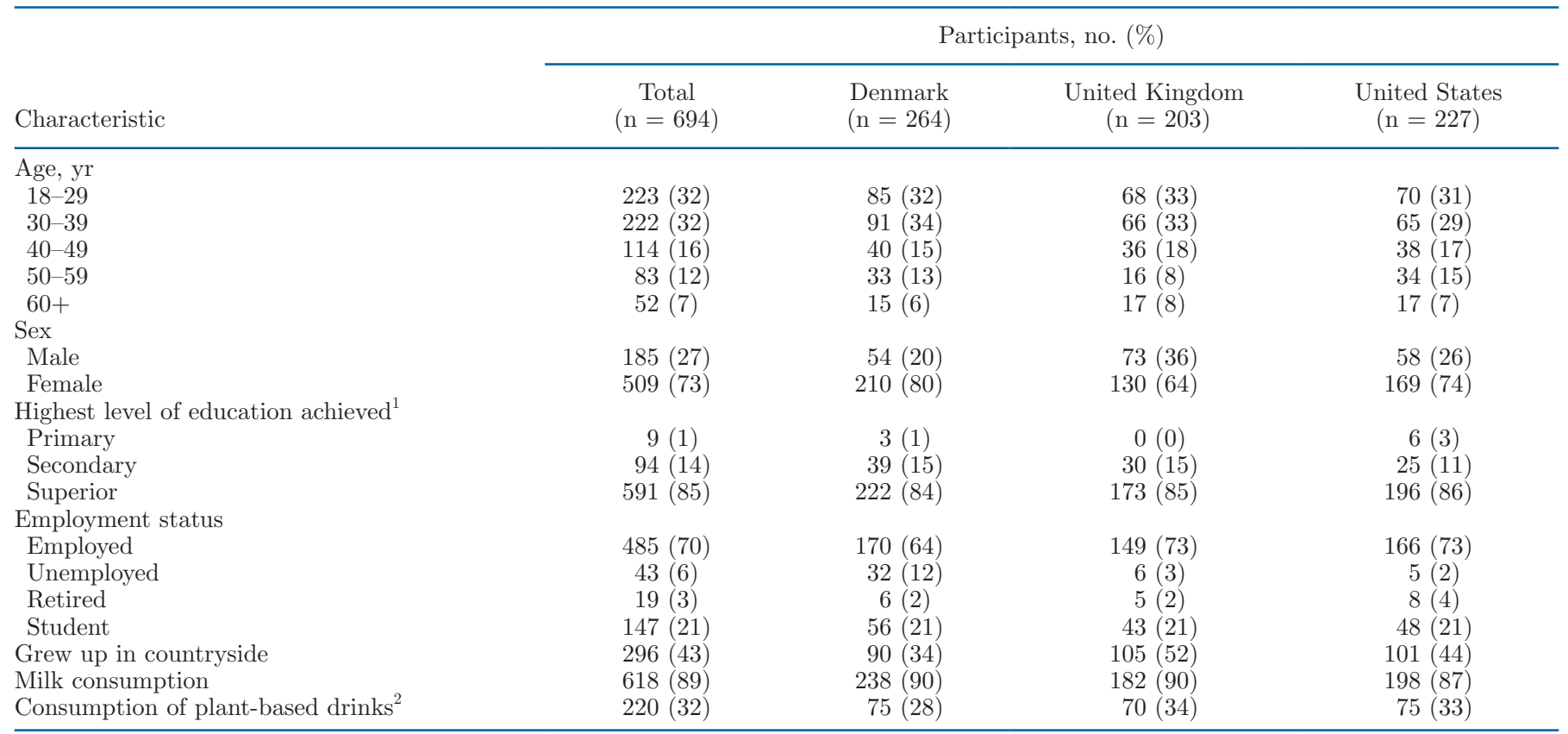

${ }^{1}$ Primary = primary education; secondary = secondary or vocational education; superior = bachelor's, master's, or PhD.

${ }^{2}$ Based on soybeans, oats, or almonds. 
of the survey. The questionnaire, which was initially developed in English, was adjusted based on feedback from the pilot survey. Two native Danish speakers translated the final questionnaire separately.

\section{Statistical Analysis}

Statistical analysis was conducted in $\mathrm{R}$ version 3.5.0 (www.r-project.org/) and Excel version 2016 (Microsoft Corp., Redmond, WA). Categorical and ordinal data were shown as frequencies and percentages. Pearson's $\chi^{2}$ tests and Fisher's exact tests were used to examine the differences in type and frequency of milk consumption, knowledge about nutrients (including fatty acid groups) in milk, and perception of milk fat between DK, UK, and the US. For significant values, post hoc pair-wise comparison tests with Bonferroni corrections were performed for multiple comparisons, to further investigate differences between countries. The threshold for statistical significance was set at $P<0.05$.

\section{RESULTS}

\section{Sociodemographic Characteristics and Milk Consumption}

A total of 694 individuals from DK $(\mathrm{n}=264)$, UK $(\mathrm{n}=203)$ and US $(\mathrm{n}=227)$ participated in this study.

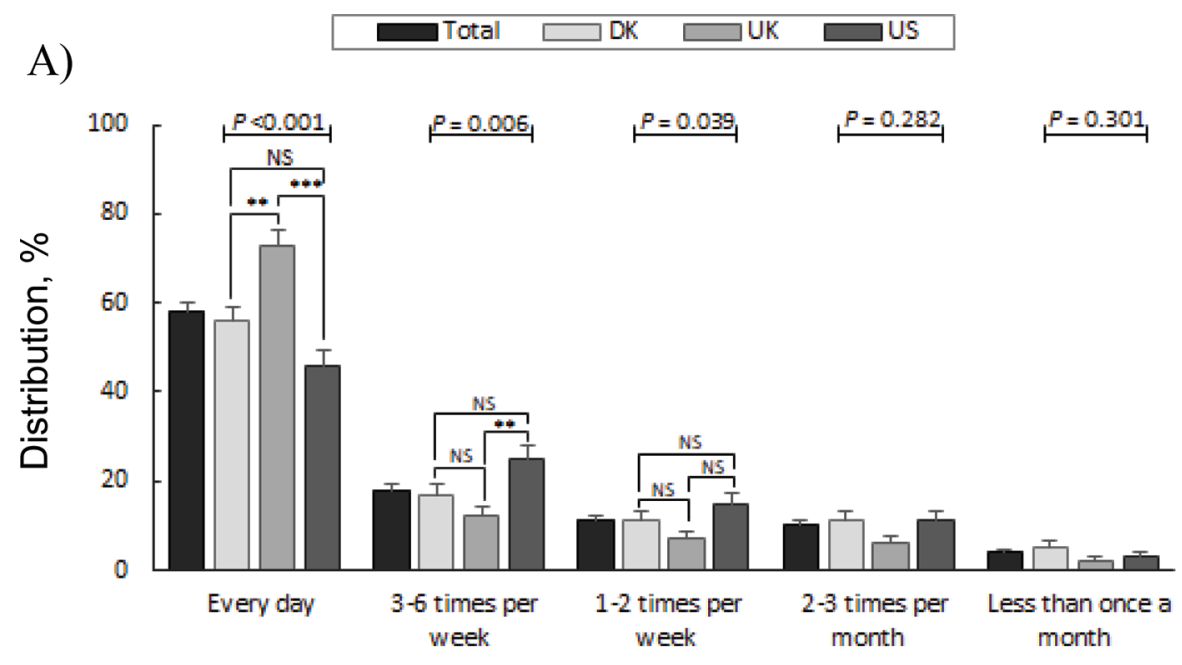

B)

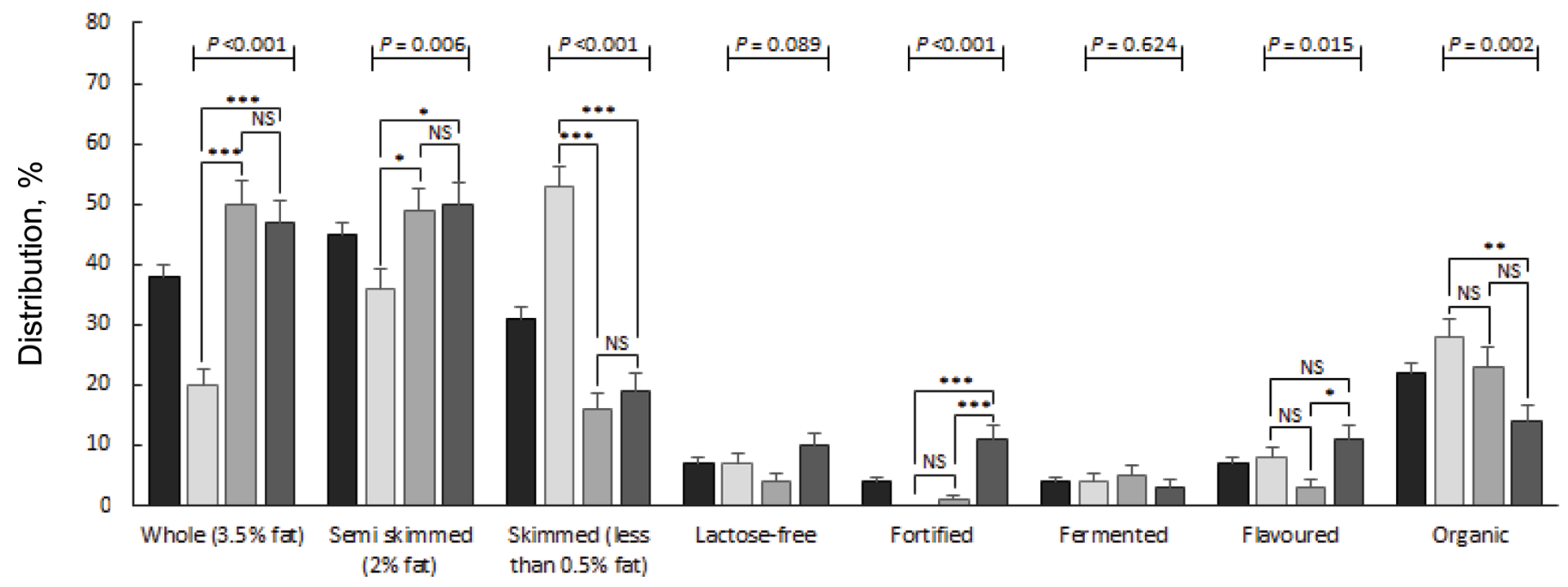

Figure 1. (A) Frequency, and (B) type of milk consumption in Denmark (DK; $\mathrm{n}=238)$, the United Kingdom $($ UK; $\mathrm{n}=182)$, and the United States (US; $\mathrm{n}=198$ ). For type of milk consumption, a multiple response question with a maximum of 3 responses per participant was set. The upper $P$-values represent overall significance. Error bars represent SE for estimated percentages. The symbols shown above the bars indicate significant differences between countries (pair-wise) as follows: ${ }^{* * *} P<0.001,{ }^{* *} P<0.01,{ }^{*} P<0.05$. 
Most respondents were aged between 18 and $39 \mathrm{yr}$, female, highly educated, and employed. Almost all participants in DK (90\%), the UK (90\%), and the US $(87 \%)$ consumed milk (Table 2). The majority of UK respondents consumed milk every day $(73 \%)$, but consumption was significantly lower $(P<0.001)$ in the DK $(56 \%)$ and US (46\%). More US (25\%) respondents consumed milk $(P=0.006)$ multiple times per week than did respondents from the UK (12\%; Figure 1A). Whole milk and semi-skim milk were consumed less frequently $(P=0.006)$ in DK (20 and $36 \%$, respectively) than in the UK (50 and 49\%, respectively) or the US (47 and $50 \%$, respectively). Skim milk was consumed more frequently $(P<0.001)$ by DK respondents $(53 \%)$ than by respondents from the UK $(16 \%)$ or the US (19\%; Figure 1B). A minority of the total sample (32\%) consumed plant-based drinks (e.g., based on oats or soybeans; Table 2).

\section{Knowledge and Perception of Nutrients in Milk}

Awareness of saturated milk fat was significantly higher $(P=0.008)$ among respondents from the UK $(53 \%)$ than among respondents from DK $(44 \%)$ or the US (38\%). Awareness of trans fat was low in all 3 countries (DK 9\%; UK, 8\%; US, 4\%). Many respondents from DK (47\%), UK (35\%), and the US (45\%) said that they did not know about any types of milk fat (Figure 2). Calcium was perceived as an important milk nutrient in DK (38\%), UK (49\%), and the US (45\%). Carbohydrates (including lactose) were considered less important in DK (19\%), UK (24\%), and the US (26\%). Both energy and carbohydrates were considered important by $23 \%$ of the total sample who responded "I don't care" (Figure 3).

\section{Perception of Milk Fat}

More DK respondents $(60 \% ; P<0.001)$ were concerned about milk fat than respondents from the UK $(34 \%)$ or the US (31\%; Figure 4A). Milk fat was perceived as "healthy" or "very healthy" by many respondents from the UK (31 vs. 10\%, respectively) and the US (37 vs. 19\%, respectively), but by fewer respondents in DK (23 vs. 6\%, respectively). More respondents from DK (31\%) reported that milk fat was "neither healthy nor unhealthy" than respondents from the UK (15\%) or the US (15\%). A minority of the total sample considered milk fat "unhealthy" (5\%) or "very unhealthy" (1\%; Figure 5). About half of respondents from DK (46\%), the UK (46\%), and the United States (56\%) said that milk fat was "tasty" (Figure 4B).

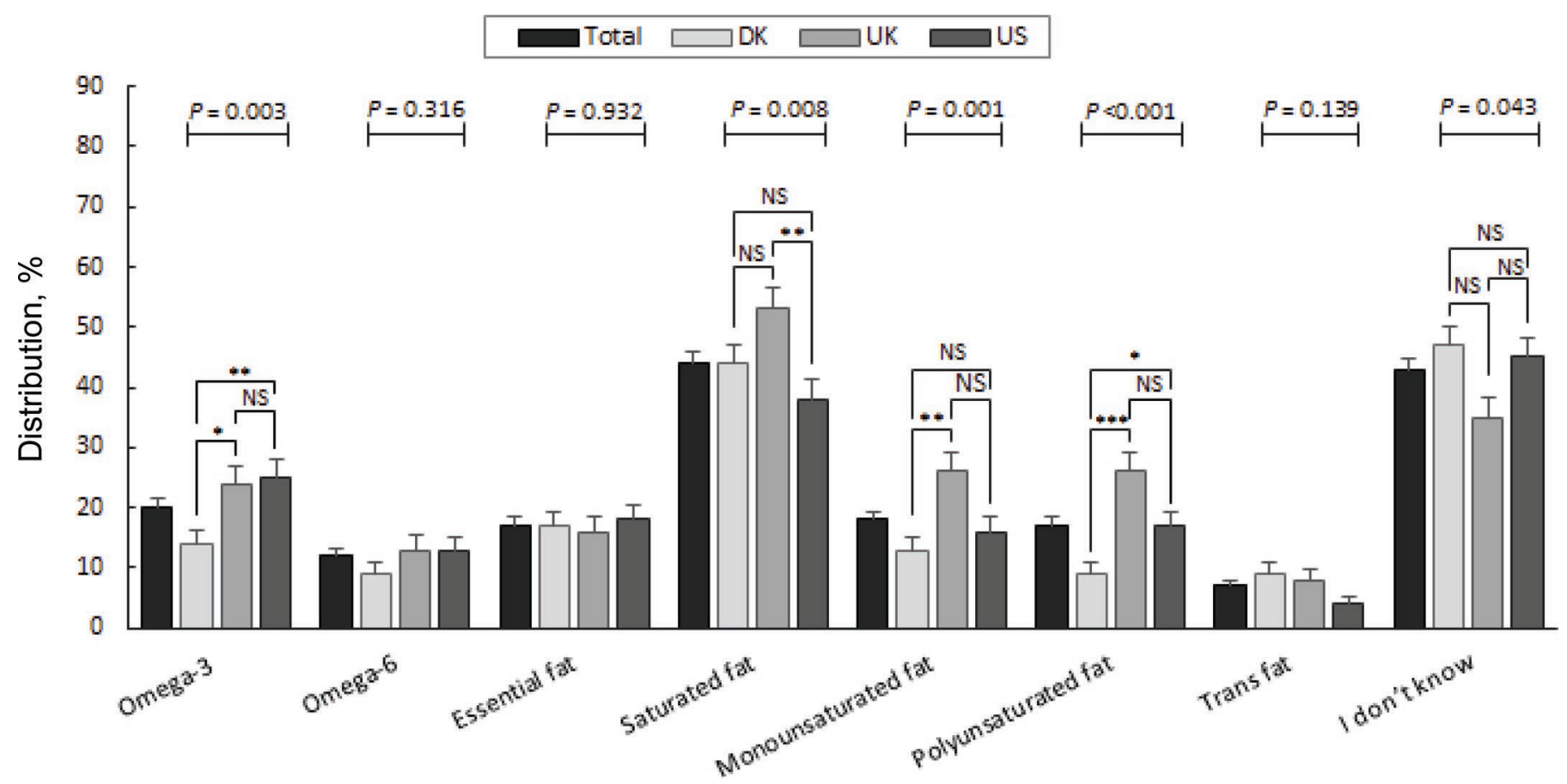

Figure 2. Reported awareness of types of fat in milk by participants from Denmark (DK; $\mathrm{n}=264)$, the United Kingdom (UK; $\mathrm{n}=203$ ), and the United States (US; $\mathrm{n}=227$ ). A multiple response question with a maximum of 3 responses per participant was set. The upper $P$-values represent overall significance. Error bars represent SE for estimated percentages. The symbols provided above the bars indicate significant differences between countries (pair-wise) as follows: ${ }^{* * *} P<0.001,{ }^{* *} P<0.01,{ }^{*} P<0.05$. 
Nutritional benefit was the most important reason for respondents to perceive milk fat as healthy, and this did not differ significantly between the US $(67 \%)$, the UK (59\%), and DK (58\%). Only $6 \%$ of all respondents considered "lower risk of diabetes" as a reason for perceiving milk fat as healthy (Figure 6A). "Cholesterol level" was an important reason for perceiving milk fat as unhealthy; this finding was significantly higher $(P$ $=0.015)$ in the UK $(80 \%)$ than in DK $(51 \%)$ and the US (64\%). In DK and the US, we found variations in the reasons for perceiving milk fat to be unhealthy. A minority of respondents considered cancer and diabetes to be the reasons for perceiving milk fat as unhealthy (Figure 6B).

Most respondents from DK (37\%), the UK (44\%), and the US (43\%) indicated education (e.g., school or university) as a source of information about milk fat. Social media was the least important source of information in DK (8\%), the UK (8\%), and the US $(6 \%$; Figure 7A). The majority of respondents were not seeking healthy eating advice; this finding was significantly higher $(P<0.001)$ for respondents from DK $(81 \%)$ and the UK $(82 \%)$ than for respondents from the US $(60 \%)$. More $(P<0.001)$ respondents from the US vis-

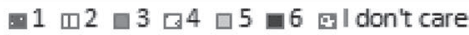

\section{A) Total of participants}

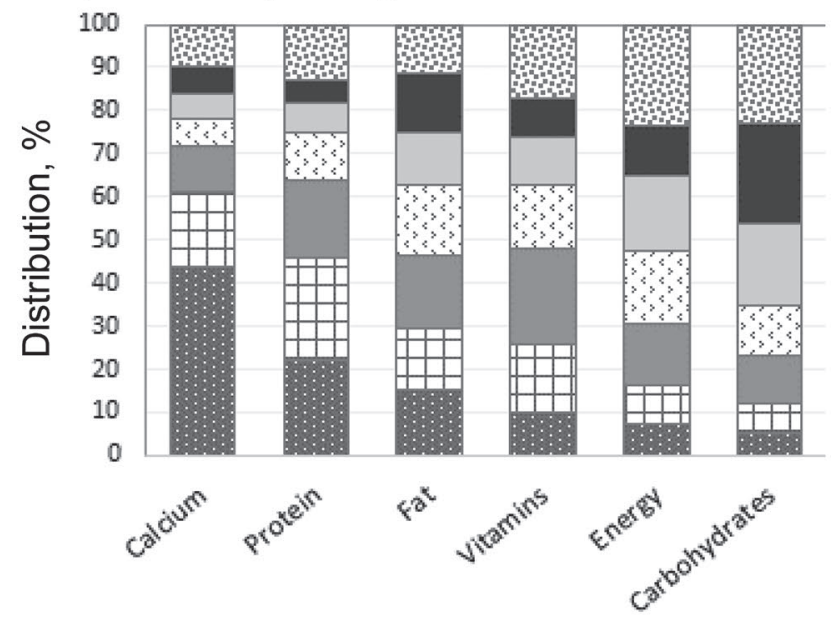

C) United Kingdom

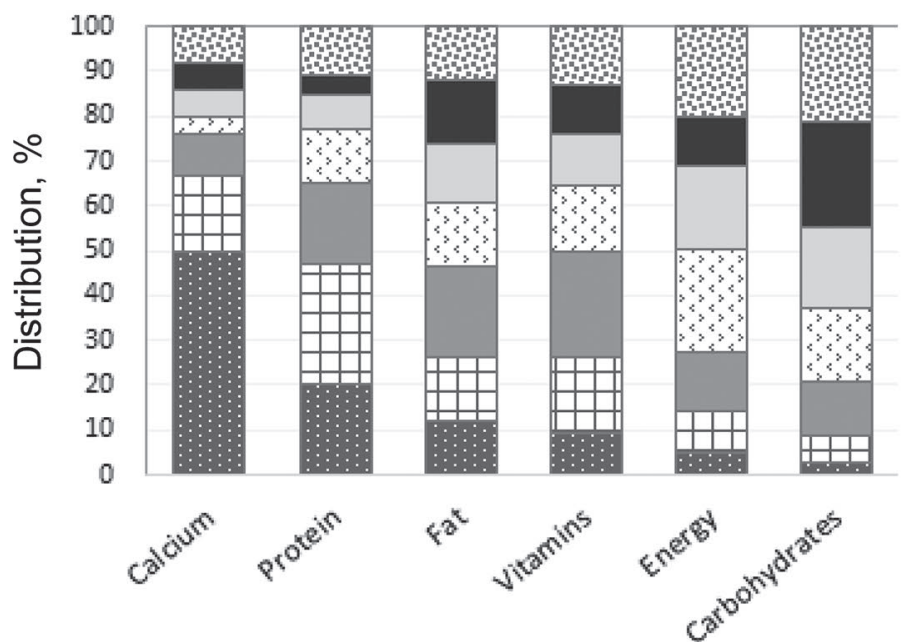

\section{B) Denmark}

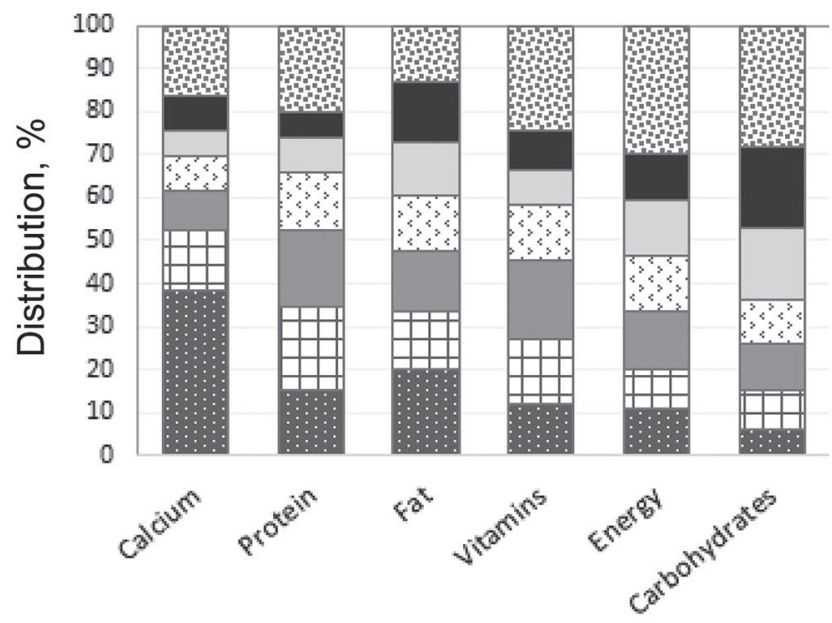

D: United States

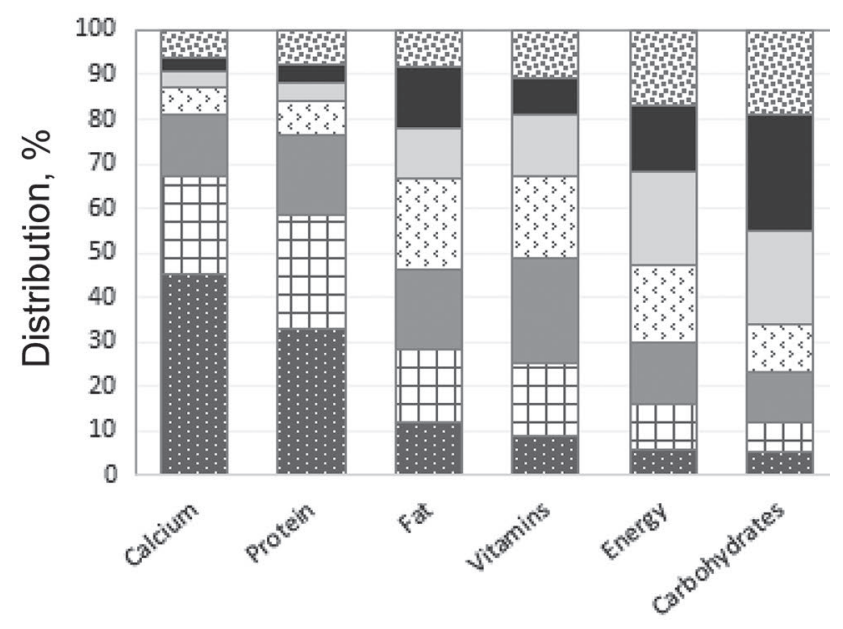

Figure 3. Reported prioritized nutrients [calcium, protein, fat, vitamins, energy, and carbohydrates (including lactose)] of milk for (A) the total sample $(\mathrm{n}=694)$ and stratified by country: (B) Denmark (DK; $\mathrm{n}=264)$, (C) the United Kingdom (UK; $\mathrm{n}=203)$, and (D) the United States (US; $\mathrm{n}=227)$. Response options ranged from 1 (most important) to 6 (least important), and "I do not care." 
ited general practitioners and dietitians for healthy eating advice (24 and $22 \%$ respectively) than respondents from DK (13 and 9\%, respectively) or the UK (11 and $7 \%$, respectively; Figure 7B).

Finally, most respondents from DK (42\%), the UK (44\%), and the US (47\%) reported being willing to pay more for milk with healthier fat content, and this did not significantly differ $(P=0.611)$ among countries. A minority (23\%) of respondents answered "I don't care" for this question.

\section{DISCUSSION}

This study aimed to investigate whether adults from DK, the UK, and the US adults differed in their knowledge and perceptions of milk fat. Milk is an important part of the Western diet (Nguyen et al., 2019), and this was reflected in the daily consumption reported by respondents to this study. Our results showed that whole, semi-skim, and skim milk were the most common types of milk consumed by the individuals surveyed, but DK respondents drank less whole and semi-skim milk and more skim milk than respondents from the UK and US. In the UK, the Department for Environment, Food and Rural Affairs (Defra, 2015) reported that since 1990, the quantity of fat-reduced milk consumption has exceeded that of whole milk, and the trend of replacing whole milk with fat-reduced milk has continued. However, since 2012 the consumption of semi-skim and skim milk has started to decrease slightly, and consumption of whole milk has slowly gone up. In the US over the past $40 \mathrm{yr}$, whole milk sales have been higher than nonfat (skim) milk sales (USDA, 2012). In DK, the consumption of whole milk and semi-skim milk has dropped since 2003, and consumption of skim milk has increased (Pedersen et al., 2015).

In our study, saturated fats, followed by omega-3 (n3) fatty acids, were the most commonly known milk fat components across all countries. Similar to our results, a large consumer study (Diekman and Malcolm, 2009) working with data from 16 countries also reported that SFA and n-3 fatty acids are the best-recognized fatty acids. In DK, the main sources of SFA are dairy products, followed by butter-based spreads, meat products, and sweet bakery products, among others (Nordic Nutrition Recommendations, 2012). The Danish regulation (Nordic Nutrition Recommendations, 2012) on intake of SFA is limited to less than $10 \%$ of overall dietary energy intake. In the US diet, saturated fats are an overconsumed nutrient, and that has led to the development of recommendations to lower saturated fat intake (USDA-DHHS, 2015). In the UK, about $27 \%$ of overall saturated fat intake comes from milk and dairy products (Hobbs et al., 2019). Interestingly, Schönfeldt et al. (2012) reported that nutritional composition is part of the basis for consumers' education about milk. They found that the largest differences in milk composition between countries such as DK, the UK, and the US were in total fat content $(3.5,3.9$, and $3.25 \%$, re-

$\square$ Total $\square$ DK $\square$ UK $\square$ US

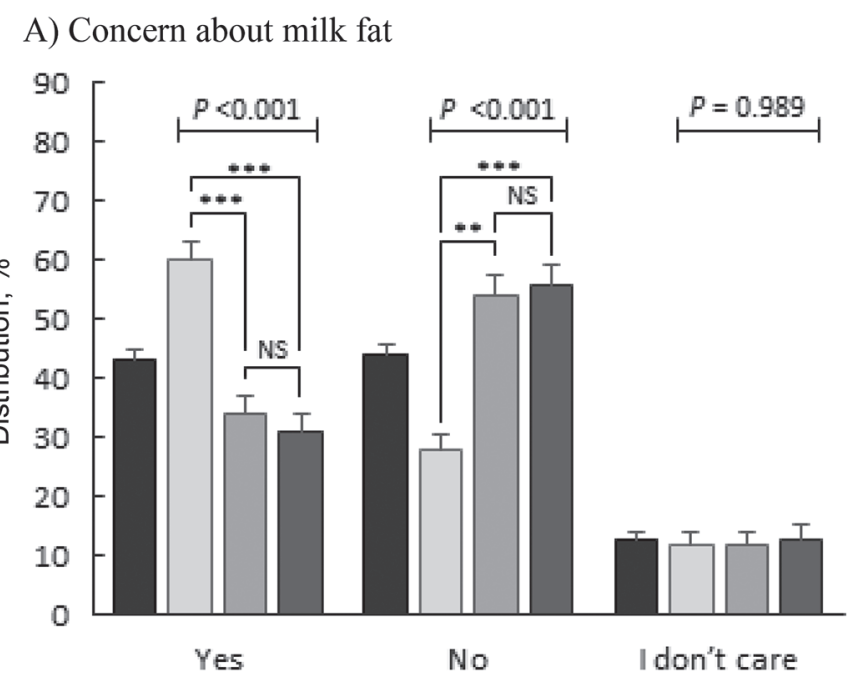

B) Perception of concepts toward milk fat

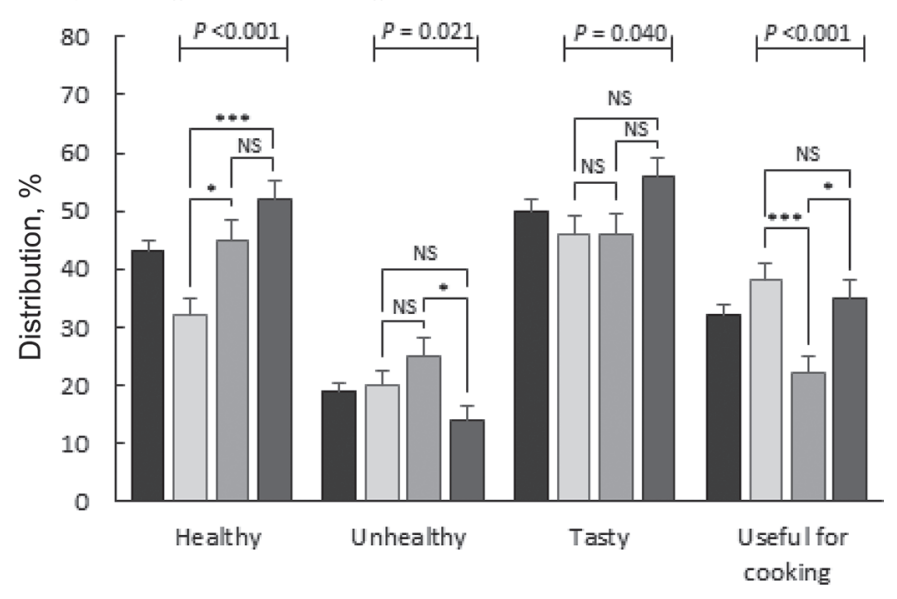

Figure 4. (A) Perceived concerns about milk fat and (B) perception of the concepts "Healthy," "Unhealthy," "Tasty," and "Useful for cooking" with respect to milk fat among participants from Denmark (DK; $\mathrm{n}=264)$, the United Kingdom (UK; $\mathrm{n}=203)$, and the United States (US; $n=227$ ). A multiple response question with a maximum of 3 responses per participant was set. Responses to the open response option "Other" included I don't know; I don't need it; calories; good with coffee; depends on consumption amount; dislike taste of high-fat milk; vitamins; needs depend on age; nutritious; health complaints; mouthfeel; component of milk; saturated fat; depends on purpose; prefer different fat percentages; prefer low fat milk. The upper $P$-values represent overall significance. Error bars represent SE for estimated percentages. The symbols provided above the bars indicate significant differences between countries (pair-wise) as follows: $* * * P<0.001,{ }^{* *} P$ $<0.01,{ }^{*} P<0.05$. 
spectively). For DK, the UK, and the US, the total SFA contents were $1.87,2.3$, and $2.4 \mathrm{~g} / 100 \mathrm{~g}$, respectively.

All respondents agreed that calcium is the most important nutrient in milk. This finding was expected, because consumers usually see milk as a good source of calcium because of its role in bone health (Bus and Worsley, 2003). In other studies, fat is usually at the top of the list of consumer nutrition concerns (Diekman and Malcolm, 2009). In countries such as the US, increasing consumption of dairy foods is seen as a means of increasing the intake of micronutrients (i.e., calcium, magnesium, and vitamin A; Scholz-Ahrens et al., 2019). In this context, it is important to note that unlike in Europe, milk in the US milk is fortified with vitamin $\mathrm{D}$, but consumers are unaware of this fact (Quann et al., 2015).

The majority of respondents declared that they obtained most of their information about milk fat from their formal education. This finding can be partly explained by the fact that the survey was circulated among academic communities. Our results were in line with those of Emrich and Mazier (2009), who surveyed university students about their knowledge of fats and reported that students who were not majoring in nutrition should take a short nutrition course to increase their awareness of their own dietary choices. Most respondents in our study were not seeking nutritional advice; respondents from the US were slightly more interested in nutritional advice, but interest was lower among respondents from DK and the UK. Whether this was a consequence of the healthcare system (e.g., private-driven advice in the US; Berchick et al., 2018) compared to public healthcare in DK (Mainz et al., 2019) and the UK (Powell, 2019), or the relative permeation of other means of communication or other sociological factors was not clear from this study and requires further research.

Differences between the surveyed countries were also reflected in respondents' concern about milk fat; specifically, respondents from DK were more concerned about this milk component than respondents from the UK and the US. In addition, DK respondents were more skeptical than respondents from the UK and the US with respect to the healthfulness of milk fat. A higher proportion of participants from DK reported a neutral perception about milk fat (i.e., neither healthy nor unhealthy), but most respondents from the UK and the US perceived milk fat to be "healthy" or "very healthy." This finding can be partly explained by the fact that consumers from different countries have different cultural factors influencing their perception of food products (Girois et al., 2001). Furthermore, consumers prioritize different factors to improve their health. In this study, results for perceptions about milk fat point to the fact that DK consumers are probably more concerned about what they eat. Similarly, Bech-Larsen

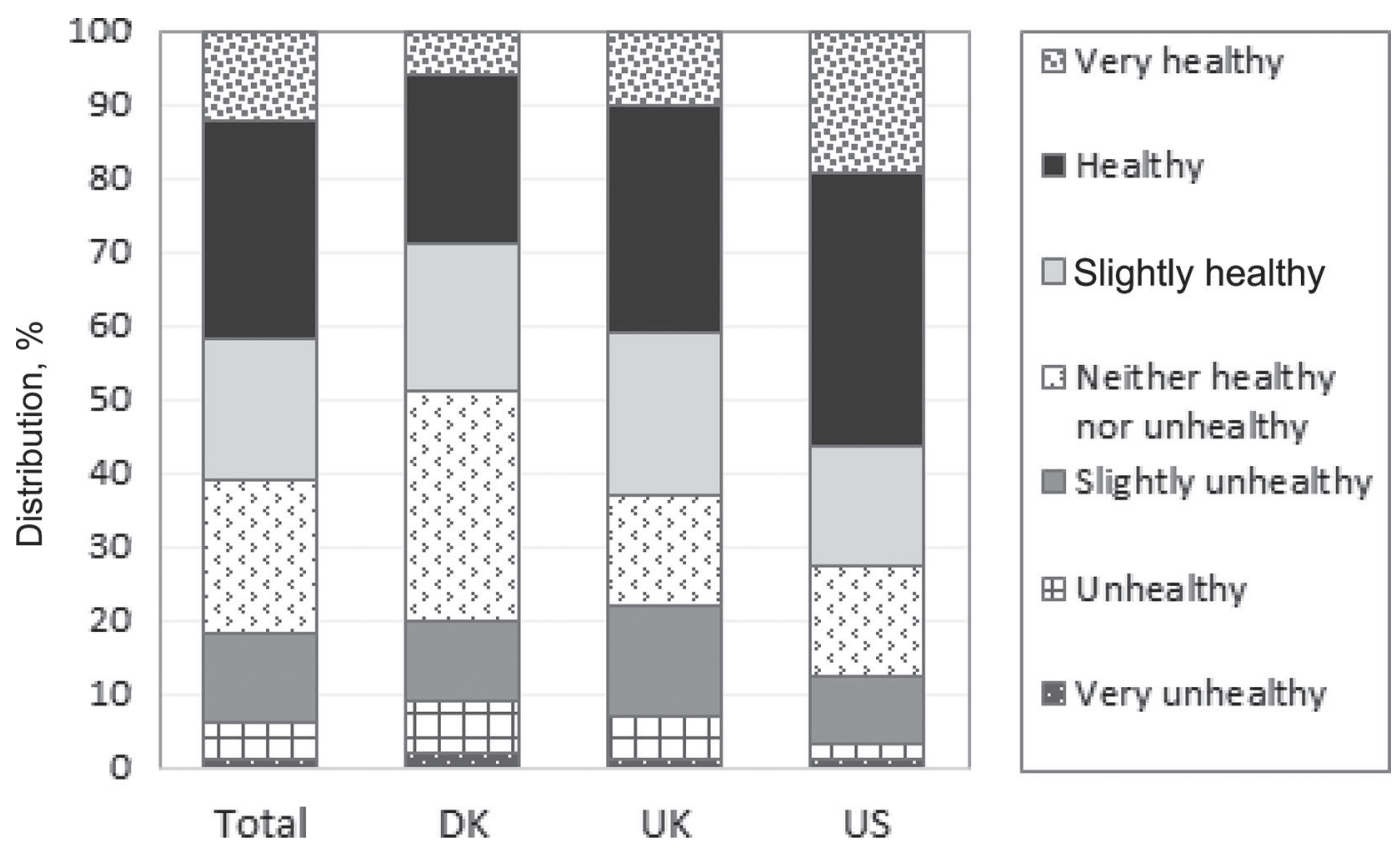

Figure 5. The extent to which participants from Denmark (DK; $\mathrm{n}=264)$, the United Kingdom (UK; $\mathrm{n}=203)$, and the United States (US; $\mathrm{n}=227)$ perceive milk fat as healthy or unhealthy. 
et al. (2001) in a consumer study aimed at comparing food preferences for functional foods between DK, the US, and Finland reported that for DK consumers, the importance of diet was pivotal, whereas for US consum- ers regular exercise was the most important factor in the pursuit of health.

In the present study, more than half of the total respondents reported that milk fat was a "tasty" com-

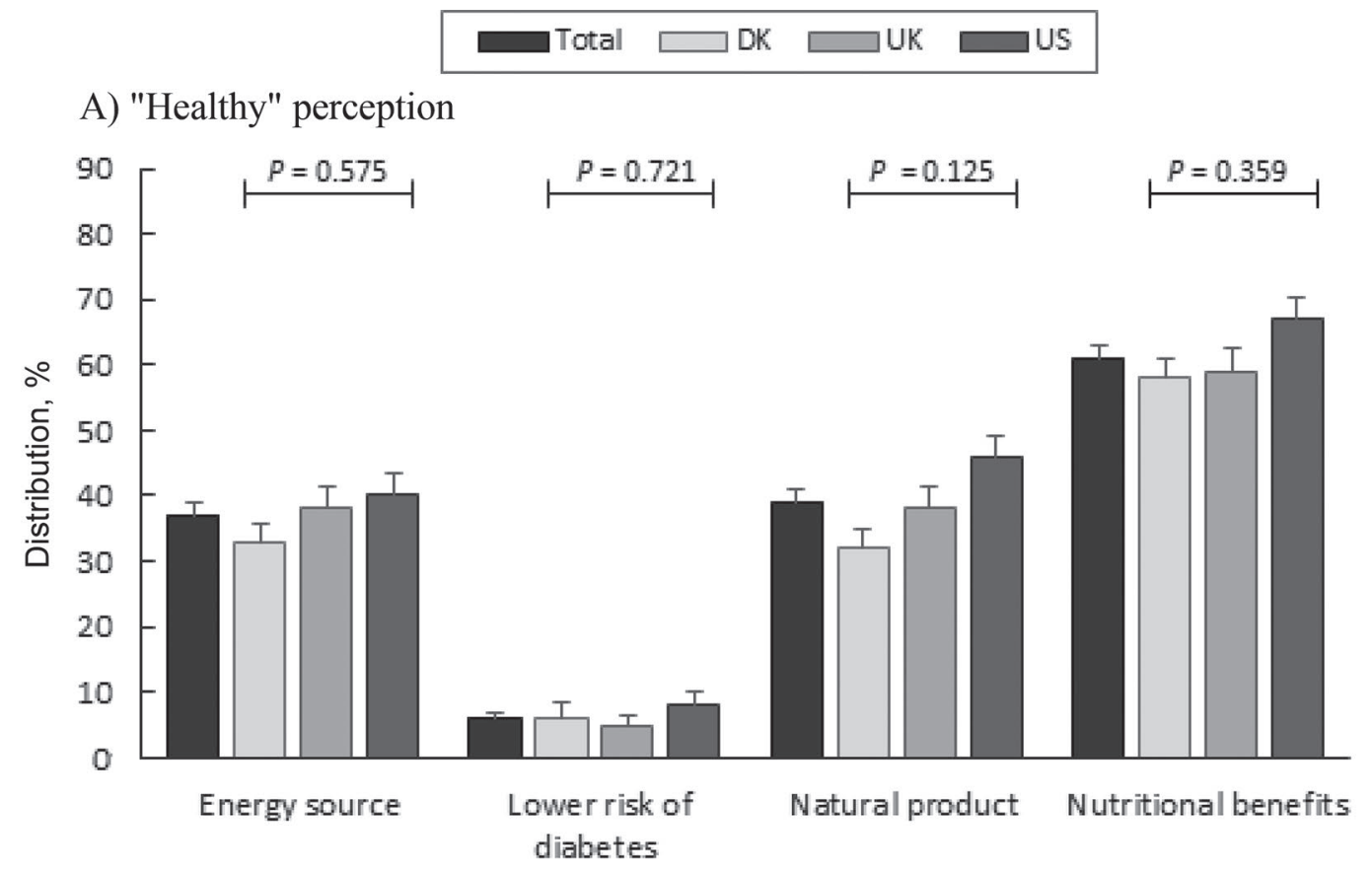

B) "Unhealthy" perception

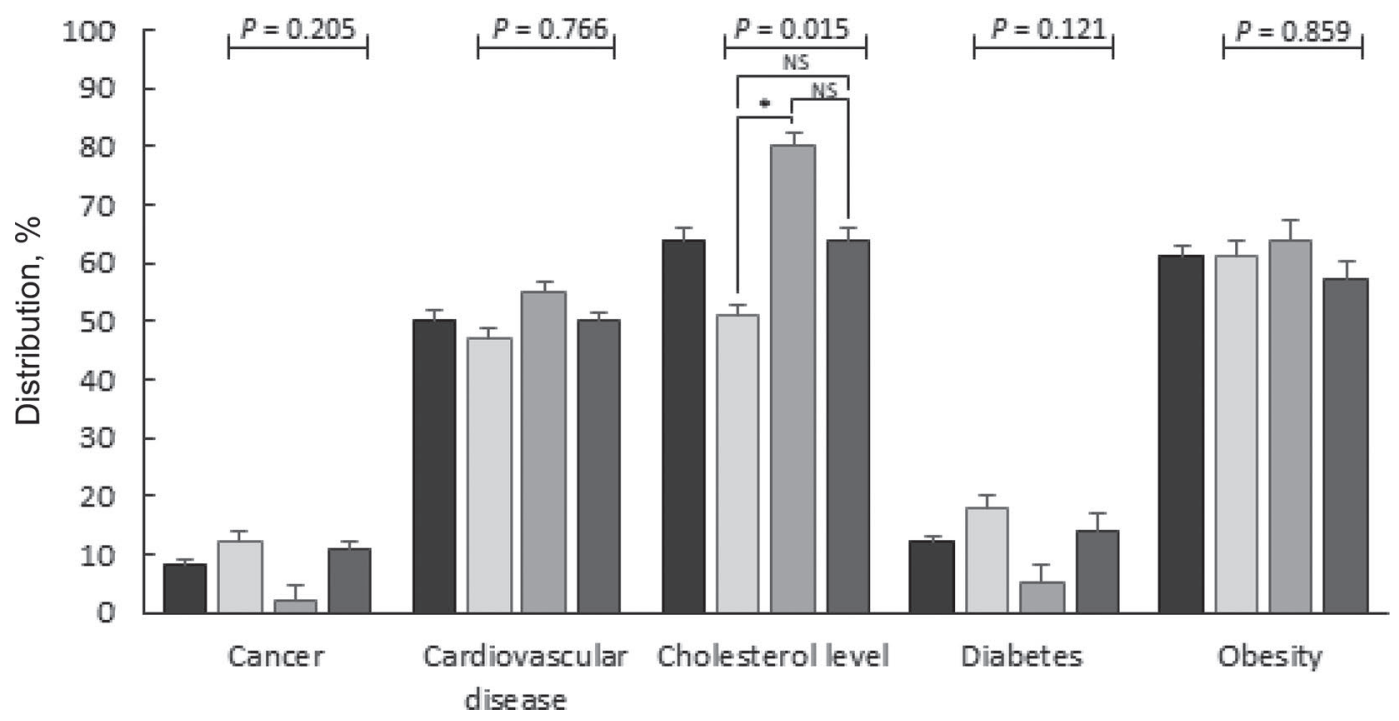

Figure 6. Reported reasons for considering milk fat (A) "Healthy" by participants from Denmark (DK; n = 100), the United Kingdom (UK; $\mathrm{n}=95)$, and the United States (US; $\mathrm{n}=100)$ or $(\mathrm{B})$ "Unhealthy" by participants from Denmark $(\mathrm{n}=51)$, the United Kingdom $(\mathrm{n}=44)$, and the United States $(\mathrm{n}=28)$. A multiple response question with a maximum of 3 responses per participant was set. Responses to the open response option "Other" included (A) essential fatty acids, health benefits, vitamins, fatty acid profile, depending on consumption amount, depending on macronutrient composition, satiating, needed in daily diet, depending on type of fat, low fat, omega oil in organic milk, undecided; and (B) humans are not intended to consume milk, humans cannot easily digest animal fat, saturated fat. A, B) The upper $P$-values represent overall significance. Error bars represent SE for estimated percentages. The symbols provided above the bars indicate significant differences between countries (pair-wise) as follows: ${ }^{*} P<0.05$. 
ponent. This finding was expected, because milk fat contributes to flavor (Phillips et al., 1995) and is associated with the desirable consumer attribute of creaminess (McCarthy et al., 2017).
Participants who reported that milk fat was "unhealthy" related it to obesity, cholesterol, and cardiovascular disease. According to Bus and Worsley (2003), the most common reasons for perceiving milk fat to
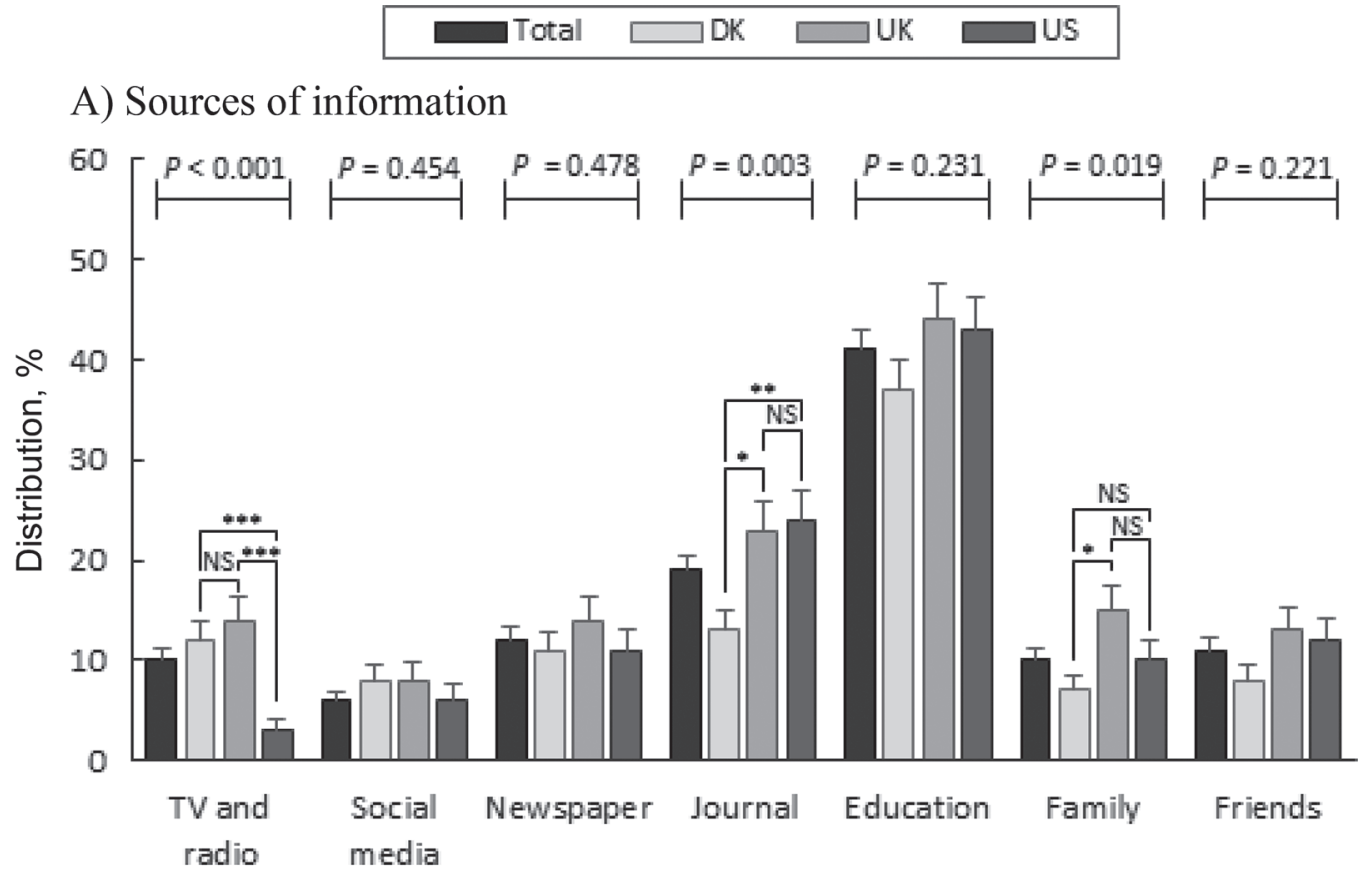

B) Healthy eating advice

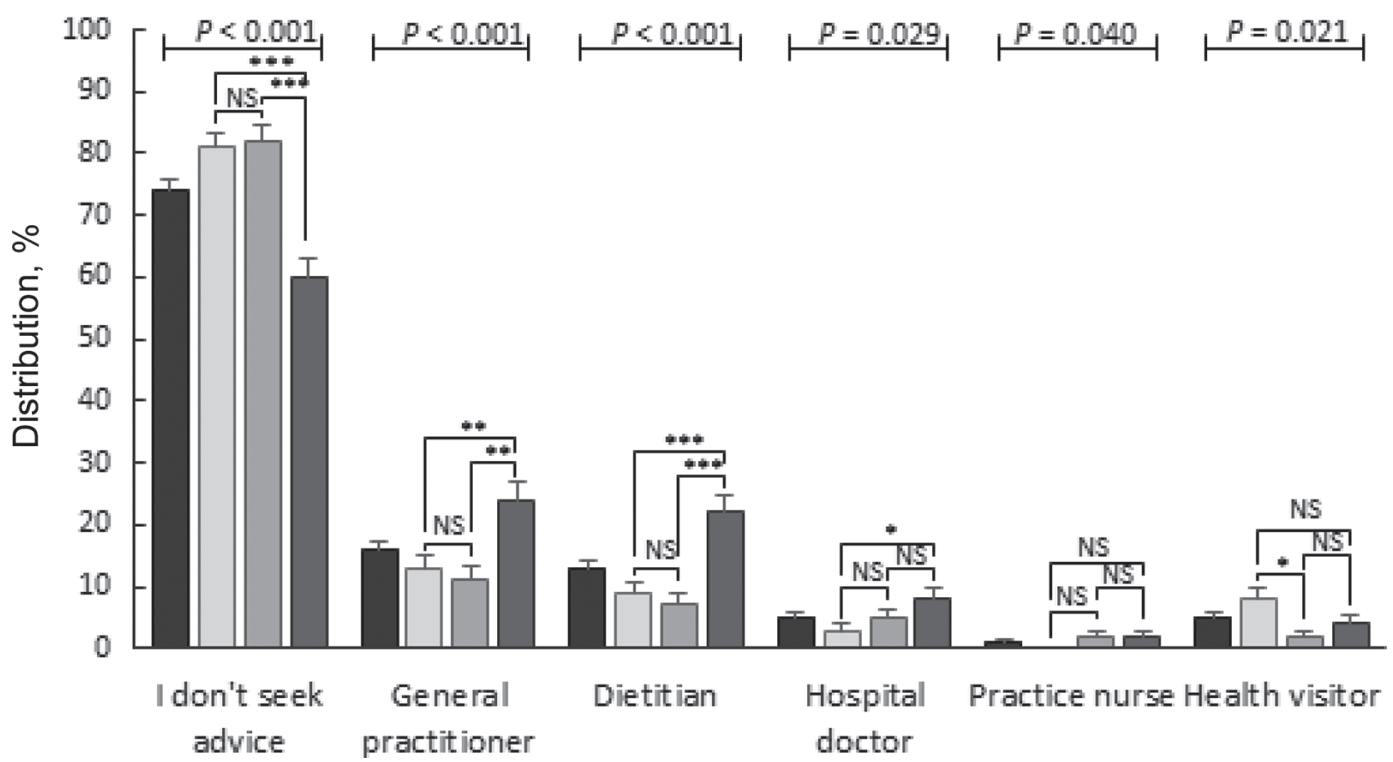

Figure 7. (A) Source of information about milk fat used and (B) visiting or not visiting health professionals for healthy eating advice by participants from Denmark (DK; $\mathrm{n}=264)$, the United Kingdom (UK; $\mathrm{n}=203$ ), and the United States $(\mathrm{n}=227)$. A multiple response question with a maximum of 3 responses per participant was set. The upper $P$-values represent overall significance. Error bars represent SE for estimated percentages. The symbols provided above the bars indicate significant differences between countries (pair-wise) as follows: ${ }^{* * *} P<0.001,{ }^{*} P$ $<0.01, * P<0.05$. 
be unhealthy component are its cholesterol and energy content. Food advertising in all forms of marketing may play a crucial role in health-related consumer behaviors (Pechmann and Catlin, 2016), and the dairy industry should consider this finding in their marketing campaigns.

Another explanation for the differences in concerns about and perceived healthfulness of milk fat across the surveyed countries could be a result of politics, economics, and science (Astrup, 2006). Different food policies from each country over the last 2 decades seem to have influenced consumer decisions, perceptions, and expectations related to different foods. For example, in the early 2000s, Denmark became the first country to limit intake of trans fatty acids (Stender and Dyerberg, 2004). Additionally, in DK, governmental policies have created a unique social and physical food environment by increasing the availability and quality of healthy food choices, decreasing the cost of healthy food choices, and changing sociocultural norms around food through public awareness campaigns (Cullerton et al., 2016). In the US, disparities in access to healthy food have been a topic of discussion and in some cases are related to low income and residential segregation, resulting in "food deserts" (urban areas with no access to affordable, healthy food; Walker et al., 2010). The UK government established the Public Health Responsibility Deal (2011 to 2015) intending to reduce the prevalence of diet-related diseases, and, in 2018, Public Health England introduced specific policies to reduce sugar and calorie consumption (Bandy et al., 2019). European research has reported that diet-related diseases are partly attributable to an increase in purchasing power and subsequent consumption of foods high in energy, saturated fat, sugar, and salt. In many highincome countries, diets are now dominated by highly processed foods, which represent up to $79 \%$ of energy intake (Slimani et al., 2009). This may have a strong effect on consumers' future life expectancies.

\section{Implications and Limitations}

This study provides a preliminary picture of consumer knowledge and perceptions of milk fat, although the demographics may not accurately represent the entire population of the selected countries. In this study, the surveyed individuals were mainly young females with bachelor degrees and who were currently employed. This was similar to studies done in South America (Vargas-Bello-Pérez et al., 2018), North America (Saulais et al., 2012), and Europe (Diekman and Malcolm, 2009). It has also been reported that more highly educated people, especially young women, are more likely to participate in surveys (Smith, 2008). It is important to note that although web surveys are an important tool for obtaining data diversity, they also bring bias (Couper and Miller, 2008). In the current study, we used university mailing lists, and this may have brought in statistical noise. However, because the survey was anonymous and the platform used did not allow us to trace IP addresses, it is difficult to know or estimate how many surveys were answered by university-related respondents. We do know that although surveys were sent to university emails, the overall results were comparable to similar studies in which surveys were carried out by phone (Diekman and Malcolm, 2009) or during face-to-face interviews (Diekman and Malcolm, 2009; Saulais et al., 2012).

Nevertheless, our results provide useful feedback for all stakeholders involved in milk production, as well as for the public health sector. A possible future route of exploration is ascertaining consumers' level of understanding of fat in terms of quality and quantity in the diet, because many studies have reported consumer confusion about healthy eating and fat. For the dairy industry, the data from the current study may be used as a reference tool to satisfy consumer expectations about milk fat content. For public health science, our data may be useful for identifying drivers that motivate milk consumption based on its fat content; this could be translated into more accurate labeling information to aid consumers in making healthy food choices (Schönfeldt et al., 2012).

\section{CONCLUSIONS}

Our results suggest that consumers in DK are different in their consumption of milk and perceptions of milk fat, particularly because of their preferences for skim milk and negative perceptions of milk fat; consumers in the UK and US consumed whole milk more frequently and had a more positive perception of milk fat. The best-known milk fat component in DK, the UK, and the US was saturated fat, and knowledge was highest in the UK, but knowledge of other fat components and nutrients in milk was similar across countries. These data could be used for future consumer-sensitive dairy beverage innovations, and for communication strategies at the industrial or public sector levels.

\section{ACKNOWLEDGMENTS}

Einar Vargas-Bello-Pérez thanks Khulan Bayarsaikhan (Ecole d'Ingenieurs de PURPAN, Toulouse, France) for her input during the design of the questionnaire. The authors have not stated any conflicts of interest. 


\section{REFERENCES}

Adina, C., C. Gabriela, and S. Roxana-Denisa. 2015. Country-of-origin effects on perceived brand positioning. Procedia Econ. Finance 23:422-427. https://doi.org/10.1016/S2212-5671(15)00383-4.

Astrup, A. 2006. The trans fatty acid story in Denmark. Atherosclerosis 7(Suppl. 7):43-46. https://doi.org/10.1016/j.atherosclerosissup .2006.04.010.

Bandy, L., V. Adhikari, S. Jebb, and M. Rayner. 2019. The use of commercial food purchase data for public health nutrition research: A systematic review. PLoS One 14:e0210192. https://doi.org/10 .1371/journal.pone.0210192.

Bartlett, J. E., J. W. Kotrlik, and C. C. Higgins. 2001. Organisational research: Determining appropriate sample size in survey research. Inf. Tech. Learn. Perf. J. 19:43-50.

Bech-Larsen, T., K. G. Grunert, and J. B. Poulsen. 2001. The Acceptance of Functional Foods in Denmark, Finland and the United States. MAPP Working Paper, 73. Aarhus School of Business, Aarhus, Denmark.

Berchick, E., E. Hood, and J. Barnett. 2018. Health Insurance Coverage in the United States: 2017. Current Population Reports P60264. US Government Printing Office, Washington, DC.

Bus, A. E. M., and A. Worsley. 2003. Consumers' sensory and nutritional perceptions of three types of milk. Public Health Nutr. 6:201-208. https://doi.org/10.1079/PHN2002417.

Couper, M. P., and P. V. Miller. 2008. Web survey methods introduction. Public Opin. Q. 72:831-835. https://doi.org/10.1093/poq/ nfn066.

Cullerton, K., T. Donnet, A. Lee, and D. Gallegos. 2016. Using political science to progress public health nutrition: A systematic review. Public Health Nutr. 19:2070-2078. https://doi.org/10.1017/ S1368980015002712.

DEFRA (Department for Environment, Food and Rural Affairs. 2015. Quantity of food and drink purchased for UK households. Family Food 2015. Accessed Feb. 26, 2019. https://assets.publishing .service.gov.uk/government/uploads/system/uploads/attachment _data/file/597667/ Family_Food_2015-09mar17.pdf.

Diekman, C., and K. Malcolm. 2009. Consumer perception and insights on fats and fatty acids: Knowledge on the quality of diet fat. Ann. Nutr. Metab. 54:25-32. https://doi.org/10.1159/000220824.

Emrich, T. E., and P. Mazier. 2009. Impact of nutrition education on university students' fat consumption. Can. J. Diet. Pract. Res. 70:187-192. https://doi.org/10.3148/70.4.2009.187.

Girois, S. B., S. K. Kumanyika, A. Morabia, and E. Mauger. 2001. A comparison of knowledge and attitudes about diet and health among 35-to 75-year-old adults in the United States and Geneva, Switzerland. Am. J. Public Health 91:418-424. https://doi.org/10 .2105/AJPH.91.3.418.

Hobbs, D. A., C. Durrant, J. Elliott, D. I. Givens, and J. A. Lovegrove. 2019. Diets containing the highest levels of dairy products are associated with greater eutrophication potential but higher nutrient intakes and lower financial cost in the United Kingdom. Eur. J. Nutr. https://doi.org/10.1007/s00394-019-01949-y.

Kearney, J. 2010. Food consumption trends and drivers. Philos. Trans. R. Soc. Lond. B Biol. Sci. 365:2793-2807. https://doi.org/10 $.1098 /$ rstb.2010.0149.

Lago-Sampedro, A., E. Garcia-Escobar, E. Rubio-Martin, N. Pascual-Aguirre, S. Valdes, F. Soriguer, A. Goday, A. Calle-Pascual, C. Castell, E. Menendez, E. Delgado, E. Bordiu, L. Castano, J. Franch-Nadal, J. Girbes, F. J. Chaves, S. Gaztambide, G. RojoMartinez, and G. Olveira. 2019. Dairy product consumption and metabolic diseases in the Di@bet.es study. Nutrients 11:E262. https://doi.org/10.3390/nu11020262.

Mainz, J., M. H. Hess, and S. P. Johnsen. 2019. The Danish unique personal identifier and the Danish Civil Registration System as a tool for research and quality improvement. Int. J. Qual. Health Care mzz008. https://doi.org/10.1093/intqhc/mzz008.

Markey, O., K. Souroullas, C. C. Fagan, K. E. Kliem, D. Vasilopoulou, K. G. Jackson, D. J. Humphries, A. S. Grandison, D. I. Givens, J. A. Lovegrove, and L. Methven. 2017. Consumer acceptance of dairy products with a saturated fatty acid reduced, monounsat- urated fatty acid-enriched content. J. Dairy Sci. 100:7953-7966. https://doi.org/10.3168/jds.2016-12057.

McCarthy, K. S., K. Lopetcharat, and M. A. Drake. 2017. Milk fat threshold determination and the effect of milk fat content on consumer preference for fluid milk. J. Dairy Sci. 100:1702-1711. https: //doi.org/10.3168/jds.2016-11417.

Nguyen, Q. V., B. S. Malau-Aduli, J. Cavalieri, P. D. Nichols, and A. E. O. Malau-Aduli. 2019. Enhancing omega-3 long-chain polyunsaturated fatty acid content of dairy-derived foods for human consumption. Nutrients 11:743. https://doi.org/10.3390/nu11040743.

Nordic Council of Ministers. 2014. Nordic Nutrition Recommendations 2012: Integrating nutrition and physical activity. 5th ed. Nordisk Ministerråd, Copenhagen, Denmark. https://doi.org/10.6027/ Nord2014-002.

OECD-FAO (Organisation for Economic Co-operation and Development-Food and Agriculture Organization of the United Nations). 2020. OECD-FAO Agricultural Outlook, Edition 2019. OECD Agriculture Statistics Database. Accessed Mar. 2, 2020. https://doi .org/10.1787/eed409b4-en.

O'Brien, N. M., and T. P. O'Connor. 2016. Milk lipids: Nutritional significance. In Reference Module in Food Science. Elsevier, Amsterdam, the Netherlands. https://doi.org/10.1016/B978-0-08-100596 $-5.00927-6$

Pechmann, C., and J. R. Catlin. 2016. The effects of advertising and other marketing communications on health-related consumer behaviors. Curr. Opin. Psychol. 10:44-49. https://doi.org/10.1016/j .copsyc.2015.12.008.

Pedersen, A. N., T. Christensen, J. Matthiessen, V. K. Knudsen, M. Rosenlund-Sørensen, A. Biltoft-Jensen, H. Hinsch, K. H. Ygil, K. Kørup, E. Saxholt, E. Trolle, A. B. Søndergaard, and S. Fagt. 2015. Danskernes kostvaner 2011-2013. Hovedresultater [Dietary habits in Denmark 2011-2013]. DTU Fødevareinstituttet, Søborg, Denmark. [In Danish].

Phillips, L. G., M. L. Mcgiff, D. M. Barbano, and H. T. Lawless. 1995. The influence of fat on the sensory properties, viscosity, and color of low-fat milk. J. Dairy Sci. 78:1258-1266. https://doi.org/ 10.3168/jds.S0022-0302(95)76746-7.

Powell, M. 2019. Seventy years of the British National Health Service: Problem, politics and policy streams. Health Econ. Policy Law 14:29-39. https://doi.org/10.1017/S1744133118000117.

Quann, E. E., V. L. Fulgoni III, and N. Auestad. 2015. Consuming the daily recommended amounts of dairy products would reduce the prevalence of inadequate micronutrient intakes in the United States: Diet modeling study based on NHANES 2007-2010. Nutr. J. 14:90. https://doi.org/10.1186/s12937-015-0057-5.

Saulais, L., M. Doyon, B. Ruffieux, and H. Kaiser. 2012. Consumer knowledge about dietary fats: Another French paradox? Br. Food J. 114:108-120. https://doi.org/10.1108/00070701211197392.

Scholz-Ahrens, K. E., F. Ahrens, and C. A. Barth. 2019. Nutritional and health attributes of milk and milk imitations. Eur. J. Nutr. https://doi.org/10.1007/s00394-019-01936-3.

Schönfeldt, H. C., N. G. Hall, and L. E. Smit. 2012. The need for country specific composition data on milk. Food Res. Int. 47:207-209. https://doi.org/10.1016/j.foodres.2011.05.018.

Slimani, N., G. Deharveng, D. A. T. Southgate, C. Biessy, V. Chajes, M. M. E. van Bakel, M. C. Boutron-Ruault, A. McTaggart, S. Grioni, J. Verkaik-Kloosterman, I. Huybrechts, P. Amiano, M. Jenab, J. Vignat, K. Bouckaert, C. Casagrande, P. Ferrari, P. Zourna, A. Trichopoulou, E. Wirfalt, G. Johansson, S. Rohrmann, A. K. Illner, A. Barricarte, L. Rodriguez, M. Touvier, M. Niravong, A. Mulligan, F. Crowe, M. C. Ocke, Y. T. van der Schouw, B. Bendinelli, C. Lauria, M. Brustad, A. Hjartaker, A. Tjonneland, A. M. Jensen, E. Riboli, and S. Bingham. 2009. Contribution of highly industrially processed foods to the nutrient intakes and patterns of middle-aged populations in the European Prospective Investigation into Cancer and Nutrition study. Eur. J. Clin. Nutr. 63(S4):S206-S225. https://doi.org/10.1038/ejcn.2009.82.

Smith, W. 2008. Does gender influence online survey participation? A record-linkage analysis of university faculty online survey response behavior (Re-search Report). San Jose State University, 
San Jose, CA. Accessed Mar. 3, 2020. https://files.eric.ed.gov/ fulltext/ED501717.pdf.

Stender, S., and J. Dyerberg. 2004. Influence of trans fatty acids on health. Ann. Nutr. Metab. 48:61-66. https://doi.org/10.1159/ 000075591.

Um, C. Y., A. Prizment, C. P. Hong, D. Lazovich, and R. M. Bostick. 2019. Associations of calcium and dairy product intakes with all-cause, all-cancer, colorectal cancer and CHD mortality among older women in the Iowa Women's Health Study. Br. J. Nutr. 121:1188-1200. https://doi.org/10.1017/S000711451900045X.

USDA. 2012. Fluid beverage milk sales quantities by product (annual) Accessed Jun. 6, 2019. www.ers.usda.gov/data-products/ dairy-data.aspx

USDA-DHHS (US Department of Health and Human Services). 2015. Scientific Report of the 2015 Dietary Guidelines Advisory Committee. US Human Nutrition Information Service, Washington, DC.

Vargas-Bello-Pérez, E., D. Enriquez-Hidalgo, P. Toro-Mujica, M. A. Fellenberg, R. A. Ibanez, and B. Schnettler. 2018. Factors affecting consumption of retail milk in Chile. Mljekarstvo 68:310-319. https: //doi.org/10.15567/mljekarstvo.2018.0406.

Vargas-Bello-Pérez, E., and P. C. Garnsworthy. 2013. Trans fatty acids and their role in the milk of dairy cows. Cienc. Investig. Agrar. 40:449-473. https://doi.org/10.4067/S0718-16202013000300001.
Walker, R. E., C. R. Keane, and J. G. Burke. 2010. Disparities and access to healthy food in the United States: A review of food deserts literature. Health Place 16:876-884. https://doi.org/10.1016/ j.healthplace.2010.04.013.

Wang, S., M. Zhou, A. Ji, D. Zhang, and J. He. 2017. Milk/dairy products consumption and gastric cancer: An update meta-analysis of epidemiological studies. Oncotarget 9:7126-7135. https://doi.org/ 10.18632/oncotarget.23496.

Yu, E., and F. B. Hu. 2018. Dairy products, dairy fatty acids, and the prevention of cardiometabolic disease: A review of recent evidence. Curr. Atheroscler. Rep. 20:24. https://doi.org/10.1007/s11883-018 -0724-z.

\section{ORCIDS}

E. Vargas-Bello-Pérez @ https://orcid.org/0000-0001-7105-5752

I. Faber @ https://orcid.org/0000-0001-7908-219X

J. S. Osorio 는 https://orcid.org/0000-0001-6192-0917

S. Stergiadis @ https://orcid.org/0000-0002-7293-182X 